\title{
Lomber Cerrahi Sonrası Gelişen Epidural Havanın Klinik Önemi
}

\section{Clinical Importance of Epidural Air After Lumbar Spinal Surgery \\ iskender Samet Daltaban', Hakan Ak', Soner Yaycıoğlu², Ali Rıza Güvercin 3 , Uğur Yazar ${ }^{3}$}

'Bozok Üni. Tıp Fakültesi Beyin ve Sinir Cerrahi AD YOZGAT

${ }^{2}$ Adnan Menderes Üni. Tıp Fakültesi Beyin ve Sinir Cerrahi AD AYDIN

${ }^{3}$ KTÜ Tıp Fakültesi Beyin ve Sinir Cerrahi AD TRABZON

Yazışma Adresi / Correspondence:

İskender Samet Daltaban

Bozok Üni. Tip Fakültesi Beyin ve Sinir Cerrahi AD YOZGAT

T: +90 $5304668473 \quad$ E-mail: isamet79@hotmail.com

Geliş Tarihi / Received : 20.02.2018 Kabul Tarihi / Accepted : 24.05.2018

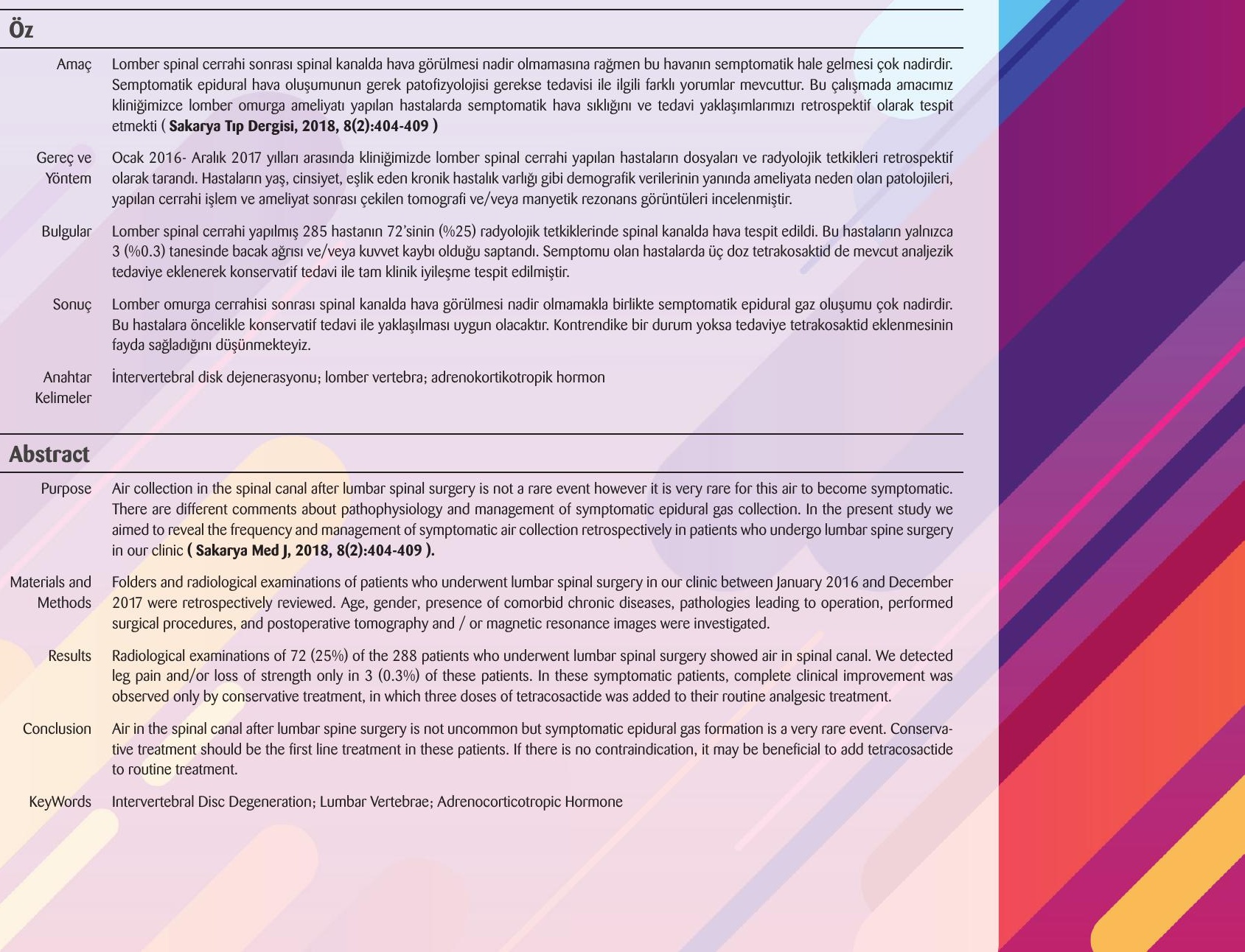


Sakarya TIp Dergisi 2018;8(2):404-409

\section{Giriş}

Kraniyoservikal travma, epidural anestezi ve perkütan spinal işlemler sonrası spinal kanalda serbest hava oluşabilmektedir. Spinal kanalda serbest hava varlığı çoğunlukla herhangi bir klinik şikayete ve/veya bulguya yol açmamaktadır.' Bununla birlikte nadiren de olsa epidural mesafeye tuzaklanan havanın klinik yakınmaya hatta nörolojik araza yol açabileceği bildirilmiştir.2 Bu konudaki literatür çoğunlukla olgu veya olgular sunumu şeklindedir. ${ }^{2,3}$ Klinik oluşturan epidural havanın oluşum mekanizması hakkında çeşitli görüşler bildirilmiş olmasına rağmen kesin mekanizma henüz ortaya konabilmiş değildir. Buna ilaveten, uygulanması gereken tedavi şekli de açık değildir. Sadece takip, iğne ile aspirasyon ve açık revizyon cerrahisi uygulanan tedavi yaklaşımları olarak bildirilmiş̧ir. ${ }^{4,5}$

Bu çalışmada kliniğimizce spinal cerrahi geçiren hastalardaki semptomatik epidural hava gelişim sıklığı, bunun klinik sonuçları ve uyguladığımız tedavi yaklaşımlarımız geriye dönük olarak araştırılmıştır.

\section{Materyal ve Metot}

Bu retrospektif tanımlayıcı, kesitsel çalışmada Bozok Üniversitesi Rektörlüğü Klinik Araştırmalar Etik Kurulu (22.11.2017 tarihli ve 2017-KAEK-189_2017.11.22_07 saylı) onayı alındıktan sonra 2016-2017 yılları arasında Bozok Üniversitesi Tıp Fakültesi Beyin ve Sinir Cerrahisi Kliniğince omurga patolojisi nedeniyle ameliyat edilen hastalar geriye dönük olarak taranmıştır. Hastaların yaş, cinsiyet, eşlik eden kronik hastalık varlığı gibi demografik verilerinin yanında ameliyata neden olan patolojileri, yapılan cerrahi işlem ve ameliyat sonrası çekilen tomografi ve/veya manyetik rezonans görüntüleri incelenmiştir. Eksik dosya bilgisi olan veya eksik radyolojik tetkiki olan hastalar çalışmaya dahil edilmemiştir. 18 yaş altı hastalar, travma nedeniyle ameliyat edilen hastalar çalışmaya dahil edilmemiştir. Cerrahi geçirmiş toplam 385 hastadan 285 tanesi çalışmaya dahil edildi. 72 hastada epidural hava belirlendi. Bu hastaların da 3 tanesinde nörolojik semptom ve defisit saptandı. Verilerin istatistik değerleri, sayı ve yüzde kullanılarak tanımlanmıştır.

\section{Bulgular}

Ocak 2016- Aralık 2017 yılları arasında omurga patolojisine yönelik olarak kliniğimizce ameliyat edilen 385 olgunun 285 tanesi çalışmaya dahil edilmiştir. Hastaların yaş aralığı 22-78 (ortanca yaş=51 ortalama yaş=56,79 standart sapma=11,813) arasında değişmiştir. 155 hastanın $(\% 54,3)$ erkek $130(\% 45,7)$ hastanın ise kadın cinsiyette olduğu belirlendi. $72(\% 25,26)$ hastada ameliyat sonrası dönemde spinal kanalda hava varlığı belirlendi. Sadece $3(\% 1,05)$ hastada epidural havanın klinik şikayet oluşturduğu tespit edildi. Bir hastada $1 / 5$ civarında kuvvet kaybı ve ağrı oluştu ancak 10 gün sonra ağrı ve kuvvet kaybı tam olarak düzeldi (resim 1). Diğer iki hastada sadece ağrı şikayeti oluştu. Benzer şekilde her iki hastanın da ağrısı 10 ve 12. günde tam olarak geçti (resim 2 ve 3). Bu hastaların hiçbirine herhangi bir invaziv girişim yapılmadı. Postop rutin tedavilerine 3 gün boyunca $1 \mathrm{mg} / g u ̈ n$ tetrakosaktid tedavisi eklenerek takip edildi. 

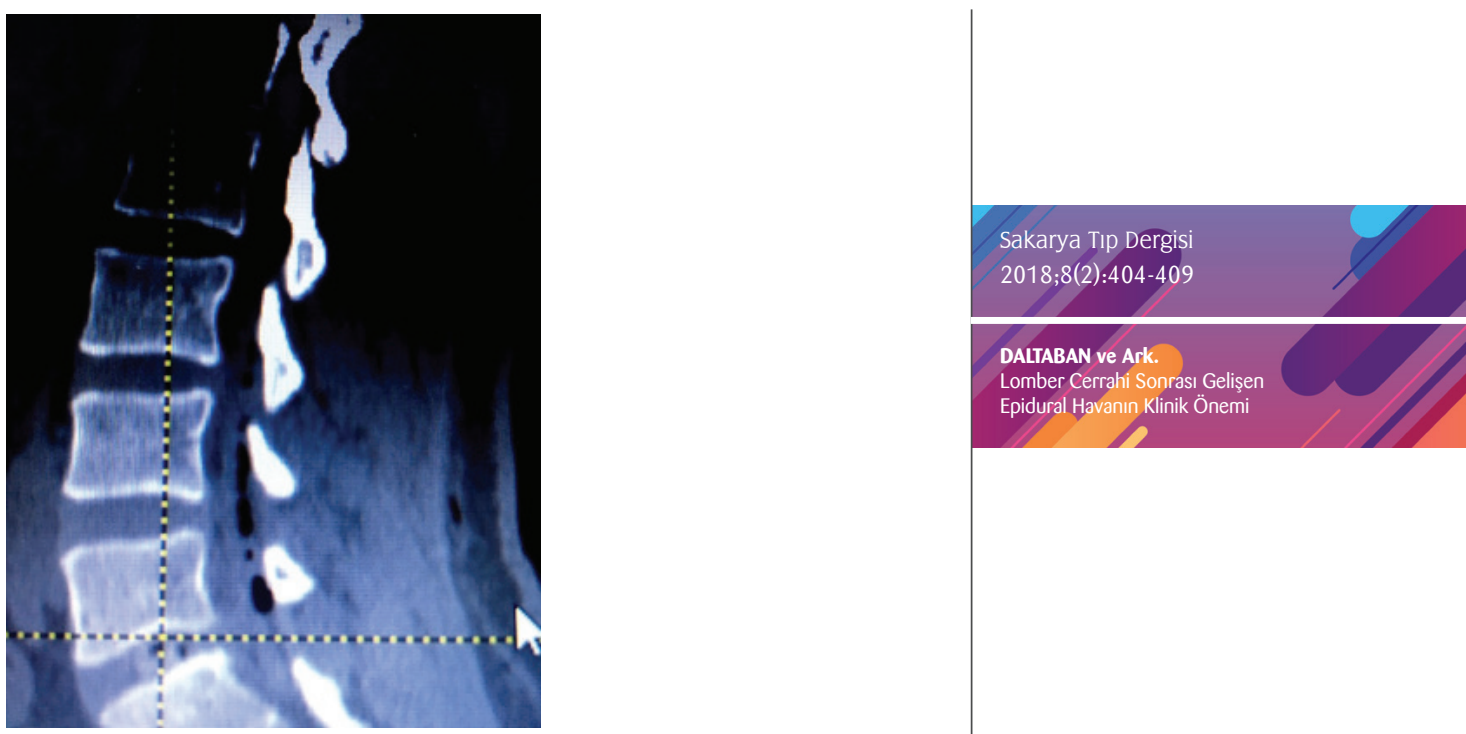

DALTABAN ve Ark.

Lomber Cerrahi Sonrası Gelișen

Epidural Havanın Klinik Önemi

Resim 1: Lomber disk herniasyonu tanısıyla sağ I5-s1 diskektomi yapılan ve I5-s1 mesafesine lomber disk protezi yerleştirilen hastanın postop 24. Saatindeki sagittal ve aksiyel lomber tomografi görüntüleri. Sagittal kesitte L5-S1 mesafesinden L3-4 mesafesine kadar uzanan epidural mesafedeki hava görülmektedir. Aksiyel kesitte sağ 15 hemilaminektomi defekti ve her iki foramene uzanım gösteren epidural hava görülmektedir.

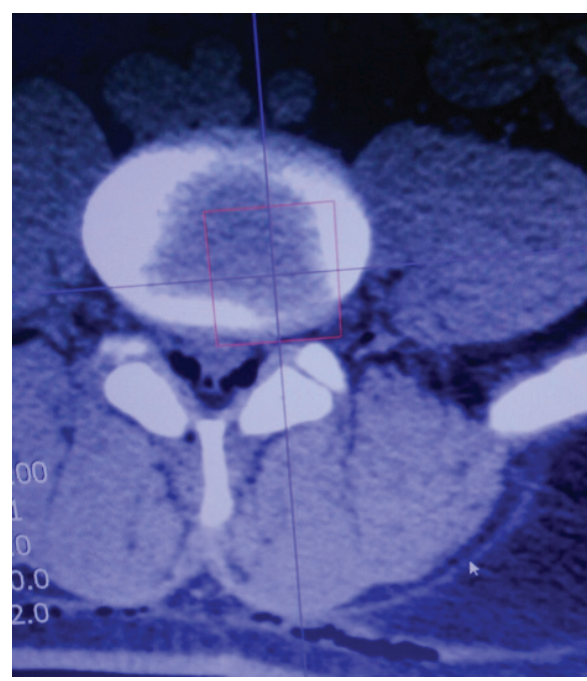

Resim2: Lomber tomografi aksiyel kesitinde epidural mesafedeki hava görülmektedir

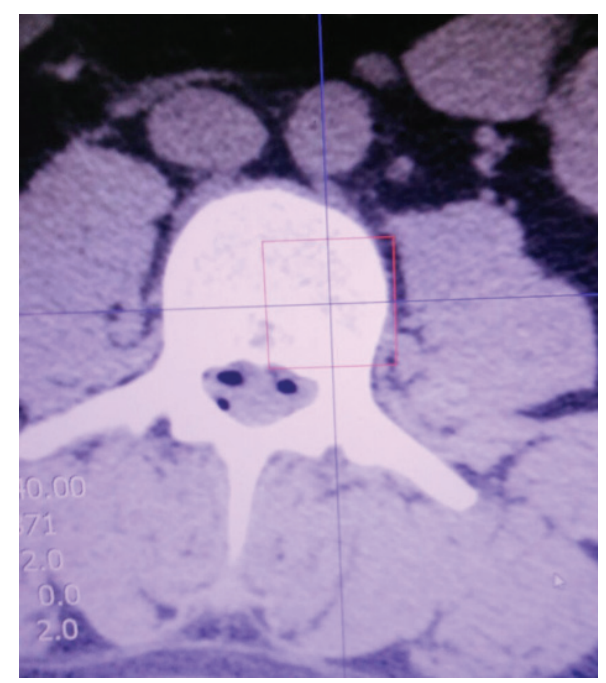

Resim3: Lomber tomografi aksiyel kesitinde epidural hava görülmektedir

\section{Tartışma}

Bu çalışmanın sonuçları lomber omurga cerrahisi sonrası spinal kanalda hava oluşmasının nadir olmadığını bununla birlikte semptomatik epidural hava oluşumunun nadir bir patoloji olduğunu göstermektedir. Bir diğer sonuçta, epidural hava oluşan hastaların yönetiminde sadece klinik gözlemin yeterli olabileceğidir.

Spinal cerrahi sonrası epidural gaz oluşumunun mekanizması ile ilgili çeşitli hipotezler ileri sürül- 
Sakarya TIp Dergisi 2018;8(2):404-409 müş olmasına rağmen kesin mekanizma halen açıklık kazanmamıştır. Bir çalışmada yazarlar, postoperatif semptomatik epidural gaz vakalarında cerrahi işlem sırasında cerrahi alan içindeki kanın yumuşak doku kenarlarının bağlanmasına neden olarak yumuşak dokuda havanın tuzaklandığını ileri sürmüşlerdir. ${ }^{3,6}$ Yazarlar bu kapanmanın, nihayetinde gaz birikimini çevreleyen bir membran oluşumuna neden olduğunu belirtmişlerdir. ${ }^{6}$ Bununla birlikte başka bir yazı da ameliyattan bir gün sonra çekilen MR'da spinal kanalda hava kabarcığının önemli bir bulgusunu tespit edememişler ve postoperatif intraspinal havanın operasyon sırasında hava tuzaklanması yerine spinal yapının kendisinden kaynaklandığı ileri sürmüşlerdir. Bu havanın ameliyattan bir süre sonra sinsice oluştuğunu ve diskin çıkarılmasıyla ilişkili olabileceğini düşünmüşlerdir.2

Çoğu yazar intraspinal havanın vakum fenomeni ile ilişkili olduğunu düşünmüşlerdir. Bazı yazarlar diskografi sonrası bilgisayarlı tomografi ile psödokiste kontrast madde akışını teyit ederek intradiskal gaz ve intraspinal gaz arasında bir ilişki bulunduğunu göstermişlerdir. İntradiskal gaz bu lomber omurganın piston gibi hareket etmesinin normal bir sonucu olarak bu iletişim yoluyla epidural alana göç edebilir ve nadiren de olsa sinir kökü sıkışmasına neden olabilir. ${ }^{6,7}$ Spinal cerrahi, epidural gaz oluşumunun önemli nedenlerinden biridir. Ancak klinik yakınma veya bulgu oluşturan postoperatif epidural gaz oluşumu çok nadirdir. 2014 yllında yayınlanan bir makalede Lee ve ark. kendi vakaları da dahil olmak üzere lomber mikrodiskektomi sonrası epidural hava gelişmiş toplam sekiz vakadan bahsetmişlerdir. ${ }^{2,4}$

Bilgisayarlı tomografi epidural hava olgularında tanı için en çok tercih edilen görüntüleme yöntemidir. Tomografi sayesinde gerek spinal kanaldaki hava birikimi gerekse diskin yapısı ve omurganın geri kalan kısmı hakkında bilgi edinilebilmektedir. ${ }^{8}$ Benzer şekilde bizim olgularımızda da öncelikli olarak hızlı çekimin yapılabilmesi ve kolay ulaşılabilirliği nedeniyle tomografi tercih edilmiştir. Manyetik rezonans görüntülemede tomografi ile benzer görüntüler vermektedir. T1 ve T2 ağırlıkı görüntülerde düşük sinyal intansitesi dikkat çekmektedir. ${ }^{9}$

Spinal cerrahi sonrası gelişen semptomatik epidural hava olgularının tedavisinde şu ana kadar literatürde bir görüş birliği sağlanabilmiş değildir. Takip, iğne ile aspirasyon ve revizyon cerrahisi bildirilen yöntemlerdir. Lee ve ark öncelikle konservatif takip ettikleri hastada şikayetlerin geçmemesi üzerine iğne ile aspirasyon yapmışlardır. Bu olgularında havanın tekrar artması üzerine revizyon cerrahisi gerçekleştirmişlerdir. ${ }^{2}$ Raynor ve Saint-Louis kas gücü kaybı gelişen 35 yaşındaki olgularında 10 gün steroid tedavisi vermişler ve 8 hafta sonra tam düzelme olduğunu belirtmişlerdir.10 Genel olarak yatak istirahati, analjezik ve/veya steroidden oluşan konservatif tedaviye cevap vermeyen olgularda iğne ile aspirasyon yapılmış olduğu gibi direk revizyon cerrahisinin yapıldığını bildiren yayınlar mevcuttur. ${ }^{3,6,10,11,12}$ Ayrıca bazı yazarlar spontan veya travmaya sekonder gelişebilecek spinal pneumorrhachiden bahsetmektedir. Özellikle kafa ve spinal travma sonrası spinal kanalda gelişen hava oluşumunun da göz önünde tutulması gerekmektedir. ${ }^{13}$ Bizim çalışmamızda travma geçiren ve spontan pneumorrhachi olabilecek hastalar çalışma dışı bırakılmışır. Yalnızca lomber cerrahi geçiren hastalar çalışmaya dahil edilmiştir.

Semptomatik hale gelen üç olgumuzun sadece birinde $1 / 5$ civarında kuvvet kaybı gelişti diğer iki hastada ise sadece ağrı ortaya çıktı. Bu hastalara üç gün günde bir kez $1 \mathrm{mg}$ tetrakosaktid (50 ünite Adrenokortikotropik hormona eşdeğer) mevcut analjezik tedavilerine eklenmiştir. Ağrı atakları tedavinin akabinde hemen düzelme göstermiştir. Kuvvet kaybı olan hastada ise 2 hafta sonraki 
kontrolünde tam düzelmenin olduğu tespit edilmiștir.

Sonuç olarak lomber omurga cerrahisi sonrası spinal kanalda hava görülmesi nadir olmamakla birlikte semptomatik epidural gaz oluşumu çok nadirdir. Bu hastalara öncelikle konservatif tedavi ile yaklaşılması uygun olacaktır. Kontraendike bir durum yoksa tedaviye tetrakosaktid eklenmesinin fayda sağladığını düşünmekteyiz.
Sakarya Tıp Dergisi

2018;8(2):404-409

DALTABAN ve Ark.

Lomber Cerrahí Sonrası Gelisen

Lomber Cerrahi Sonrası Gelișen
Epidural Havanın Klinik Önemi 
1. Hidalgo-Ovejero AM, Garcia-Mata S, Gozzi-Vallejo S. Intradural disc herniation and epidural gas: something more than a casual association? Spine 2004;29:463-67

2. Chul-Woo Lee, Kang-Jun Yoon, Sang-Soo Ha, Joon-Ki Kang. Radicula Compression by Intraspinal Epidural Gas Bubble Occurred in Distant Two Levels after Lumbar Microdiscectomy. Journal of Korean Neurosurgica Society 2014;56:6, 521.

3. Capelle HH, Krauss JK. Recurrent sciatica due to periligamentous trapped epidural gas after spinal sequestrectomy. J Neurosurg Spine 2006 4:75-77,

4. Lee DY, Lee S. L2 radicular compression caused by a foraminal extradura gas pseudocyst. J Korean Neurosurg Soc 2010;47:232-4.

5. Sung Uk Kuh, Dong Hwa Heo, Keun Su Kima, Yong Jun Cho Lumbar epidural gas-containing pseudocysts as a cause of severe radicular pain. Joint Bone Spine. 2011 Jul; 78(4):398-401.

6. Sasani M, Ozer AF, Oktenoglu T, Cosar M, Karaarslan E, Sarioglu AC. Recurrent radiculopathy caused by epidural gas after spinal surgery : report of four cases and literature review. Spine Phila Pa 2007;32:320-5
7. Kakitsubata Y, Theodorou SJ, Theodorou DJ. Symptomatic epidural gas cyst associated with discal vacuum phenomenon. Spine 2009;34:784-9.

8. Battal B, Bozlar U, Sanal HT, Saglam M, Bulakbasi N, Ustunsoz B. Symptomatic epidural gas accumulation originating from vacuum phenomenon in the intervertebral disc: CT imaging findings. The Internet Journal of Radiology. 2009:10 (1) DOI: 10.5580/1912

9. Giraud F, Fontana A, Mallet J, Sciatica caused by epidural gas: four case reports. Joint Bone Spine 2001;68:434-37

10. Raynor RB, Saint-Louis L. Postoperative gas bubble foot drop. A case report. Spine 1999;24(3):299-301

11. Kaymaz M, Oztanir N, Emmez H, Ozköse Z, Paşaoğlu A. Epidural air entrapment after spinal surgery. Clin Neurol Neurosurg 2005; 107 : 421 424 ,

12. llica AT, Kocaoglu M, Bulakbasi N, et al. Symptomatic epidural gas after open diskectomy: $\mathrm{CT}$ and MR imaging findings. AJNR Am J Neuroradiol. 2006 May;27(5):998-9.

13. Çayli SR, Koçak A, Kutlu R, Spinal pneumorrhachis.J.Neuroserg 2003; $17: 72-74$ 